\title{
TELENOVELA E TURISMO: UMA ANÁLISE ESTILÍSTICA DE O OUTRO LADO DO PARAÍSO
}

\author{
TV soap opera and tourism: a stylistic analysis of O Outro Lado do Paraíso
}

\author{
Telenovela y turismo: un análisis estilístico del O Outro Lado do Paraíso
}

José Tarcísio da S. Oliveira Filho

Professor do Programa de Pós-Graduação em Comunicação da Universidade Federal de Roraima jtarcisiofilho@gmail.com

Rafael Barbosa Fialho Martins Professor dos cursos de Jornalismo e Publicidade e Propaganda da Universidade Vale do Rio Doce rafaelbfialho@gmail.com

Natiele Lopes Costa Jornalista pela Universidade Federal de Minas Gerais natiele.lopesc@gmail.com

\section{Resumo}

Este trabalho lança mão da metodologia de Análise Estilística, conforme preconizada por Jeremy Butler, para observar como a telenovela O Outro Lado do Paraíso, exibida pela TV Globo entre os anos de 2017 e 2018, aborda o turismo na região do Jalapão, no Tocantins. É selecionado um evento narrativo que permite observar a relação entre a narrativa ficcional seriada e o turismo enquanto atividade econômica. A análise permite observar três frentes em que o apelo turístico é empregado na telenovela: I) a estrutura receptora do turista; II) cultura local como atrativo e; III) valorização das belezas naturais. Entre as considerações elencadas, refletem-se sobre a função social da telenovela que permite aos espectadores conhecer lugares distantes, a propagação de um destino idealizado que reforça a exclusão de conflitos sociais e a importância das narrativas seriadas para o setor turístico.

Palavras-chave: Narrativas Ficcionais. Telenovela. Turismo.

\section{Abstract}

This work claims the methodology of stylistic analysis, as conceptualized by Jeremy Butler, to observe how the TV soap opera O Outro Lado do Paraíso, displayed by TV Globo between 2017 and 2018, approach the tourism in the Jalapão region in state of Tocantins (Brazil). It is selected a narrative event that allows to observe the relationship between serial fictional narrative and tourism as an economic activity. The analysis allows to observe three fronts in which the tourist appeal used in the soap opera: I) the tourist reception structure; II) local culture as attractive and; III) valorization of natural beauty. Among the considerations mentioned, it reflects on the social function of the fictional narrative that allows the viewer to 
know distant places, the disclosure of an idealized destination that reinforces the exclusion of certain social groups and the importance of soap operas for the tourism sector.

Key words: Fiction Narratives. Soap Opera. Tourism.

\section{Resumen}

Este articulo utiliza la metodología del análisis estilístico, de acuerdo con la concepción de Jeremy Butler, para observar cómo la telenovela O Outro Lado do Paraíso, exhibido por TV Globo entre 2017 y 2018, aborda el turismo en la región de Jalapão, Tocantins. Se selecciona un evento narrativo que nos permite observar la relación entre la narrativa ficticia en serie y el turismo como actividad económica. El análisis nos permite observar tres frentes en los que se emplea el atractivo turístico en la telenovela: I) la estructura de recepción turística; II) cultura local como atractiva y; III) mejora de la belleza natural. Entre las consideraciones enumeradas, se refleja en la función social de la telenovela que permite a los espectadores conocer lugares distantes, la difusión de un destino idealizado que refuerza la exclusión de ciertos grupos sociales y la importancia de las narrativas en serie para el sector turístico.

Palabras clave: Narrativas Ficticias. Telenovela. Turismo.

\section{INTRODUÇÃO}

A telenovela, enquanto produto cultural midiático consolidado no Brasil, representa um importante campo de estudos e, simultaneamente, reúne milhares de pessoas em frente à televisão para acompanhar narrativas ficcionais que dialogam com situações públicas e privadas baseadas na vida real. As gravações em diferentes lugares do mundo e no próprio Brasil conseguem aproximar distâncias e apresentar culturas e cenários muitas vezes desconhecidos para o grande público, fazendo-o "viajar" sem sair do lugar. O Clone (2001/2002), América (2005), Belíssima (2005/2006), Caminho das Índias (2009), Passione (2010/2011) e Salve Jorge (2012/2013) são algumas novelas que têm como ponto em comum icônicas ambientações: Marrocos, Estados Unidos, Grécia, Índia, Itália e Turquia, respectivamente, entraram nas casas dos mais diversos espectadores. Já a Ilhéus de Gabriela, o Monte Roraima de Império, o Pará da recente A Força do Querer são exemplos de lugares do Brasil que chegaram às telas sendo cenários de folhetins da Rede Globo.

Por outro lado, as viagens, ou melhor, o turismo, enquanto atividade econômica, gera empregos, renda e impactos, e é um importante setor econômico, responsável por 10,4\% do PIB mundial (WTTC, 2018). Tendo tal panorama em vista, o presente artigo se propõe a compreender como se estabelece a relação dessas duas áreas tão diferentes: a telenovela brasileira e o turismo, se propondo a refletir sobre a seguinte questão central: como a telenovela pode ser capaz de exaltar atrativos turísticos de um destino, criando uma (possível) idealização sobre os lugares e despertando a intenção de viagem? A telenovela escolhida para 
análise foi $O$ Outro Lado do Paraíso, transmitida na faixa das 21 horas, na TV Globo, entre 23 de outubro de 2017 e 11 de maio de 2018.

$\mathrm{O}$ enredo do folhetim pode ser observado em duas fases. Na primeira, é apresentado um triângulo amoroso envolvendo a inocente protagonista Clara (Bianca Bin), o médico Renato (Rafael Cardoso) e o rico Gael (Sérgio Guizé). Clara morava com seu avô, Josafá (Lima Duarte), na região da cidade fictícia de Pedra Santa (Tocantins) e conhece Gael durante a viagem de férias do rapaz ao Jalapão, local onde ela dava aulas como professora em um quilombo - onde também trabalhava Renato. O casal Clara e Gael se apaixona rapidamente e o casamento é realizado com a bênção de Sophia (Marieta Severo), que vê na união de seu filho a chance de explorar esmeraldas que existem nas terras da nora. O protagonista, nesse momento, tem atitudes agressivas com a recém esposa na casa em Palmas, capital do Tocantins. Clara pensa em se separar, mas desiste ao descobrir uma gravidez. Já Sophia articula, com a ajuda de sua filha Lívia (Grazielli Massafera), do psiquiatra Samuel (Eriberto Leão), do delegado Vinícius (Flávio Tolezani) e do juiz Gustavo (Luís Melo), um plano para isolar Clara em uma clínica psiquiátrica e, assim, fazer a extração de pedras preciosas do terreno que agora está em nome do neto. A segunda fase tem início após a passagem de 10 anos da internação de Clara. A protagonista foge da clínica, resgata uma herança milionária e vai a Palmas em busca de vingança a todos que contribuíram para seu isolamento. Clara, dessa vez rica, faz seu retorno em uma importante festa da alta sociedade da capital. Nesse momento, a trama divide-se entre os núcleos de Palmas e de Pedra Santa, cidade onde fica localizado o garimpo de esmeraldas.

A primeira e mais evidente justificativa para a escolha do objeto empírico consiste na ambientação da narrativa, realizada no Tocantins, estado da Região Norte do Brasil. O folhetim contou com gravações no Parque Estadual do Jalapão. O destino já é considerado um ponto turístico da região, abrangendo uma área de preservação ambiental distribuídos em três municípios tocantinenses. Houve um forte investimento institucional da emissora carioca em vincular a novela à região geográfica e turística do Jalapão (por meio de matérias no site oficial da novela e uma edição temática do Globo Repórter sobre o Jalapão após o último capítulo), realizando uma interação entre ficção e realidade que, certamente, contribui para ambas as partes: ganha a telenovela, por ser ambientada em local fora do eixo Rio-São Paulo, o que acrescenta novidade e dinamismo à sinopse, que, por sua vez, amplia possibilidades de desdobramento do enredo; e ganha o turismo do Jalapão, que recebeu ainda mais visibilidade a partir da exibição da novela. 
Para dar conta da forma audioverbovisual da TV, lançamos mão da metodologia estilística televisiva desenvolvida por Jeremy Butler (2010), que nos permite identificar quais funções são desempenhadas pelos elementos que compõem o texto televisivo. Porém, antes de discutir os operadores de análise, consideramos necessária uma reflexão histórica acerca da telenovela na sociedade brasileira em articulação com o turismo.

\section{TELENOVELA, TURISMO E INTERLOCUÇÕES TEÓRICAS}

O modelo brasileiro de produção de telenovelas é composto por características que o diferem do que é praticado na América Latina. As narrativas nacionais seguem o viés realista, com diálogos coloquiais e abordagem de temas relacionados às tensões sociais de sua época. Em contrapartida, nos demais países latino-americanos a busca era por distanciamento dos conflitos que envolviam telespectadores e o país (HAMBURGER, 2011). Esse pode ser considerado um dos motivos pelas quais as telenovelas brasileiras alcançaram, nesses quase 70 anos de exibição permanente no Brasil, reconhecimento público como produto cultural e espaço de relevância como tema de estudos. As telenovelas conquistaram a capacidade de alimentar um repertório comum entre pessoas diferentes que "se posicionam e se reconhecem umas às outras" (LOPES, 2003, p. 18), além de também serem responsáveis por criarem um novo espaço público ao oferecer repertório acessível à vários públicos.

A relação entre a telenovela e as diferentes representações da sociedade brasileira se explicita, de acordo com Hamburger (2011), nos momentos em que a competição entre emissoras se apresenta na disputa entre versões diferentes de Brasil retratadas na narrativa. Essa competição envolvendo as narrativas televisivas é consolidada principalmente a partir da década de 90 com a concorrência entre Globo, que trazia a modernidade como marca, e a Rede Manchete, que vinha em oposição a anterior, com a exibição de séries e telenovelas que tinham o Brasil rural como tema. Na década seguinte, a disputa passou a ser entre as redes Globo e Record.

Por sua vez, o termo turismo possui perspectivas variadas conforme diferentes organizações, pesquisadores e legislações. Nota-se, que apesar de definições formuladas por diferentes autores, elas se complementam. $\mathrm{O}$ turismo ${ }^{1}$ contemporâneo pode ser visto como

\footnotetext{
${ }^{1}$ No Brasil, a Lei 11.771 de 2008, que trata sobre a Política Nacional de Turismo, em seu segundo artigo, considera o turismo como sendo "as atividades realizadas por pessoas físicas durante viagens e estadas em lugares diferentes do seu entorno habitual, por um período inferior a 1 (um) ano, com finalidade de lazer, negócios ou outras" (BRASIL, 2008, p. 1). Em seguida, em parágrafo único, o texto destaca que tais estadas devem gerar movimentação econômica, emprego e renda (BRASIL, 2008).
} 
destinos organizados fisicamente, que recorrem a recursos comunicacionais voltados para a divulgação - sendo a tecnologia uma aliada importante nesse processo. É assumir que a midiatização da sociedade (HJARVARD, 2012) também perpassa pelo setor turístico. As cidades, para serem consideradas turísticas recorrem à mídia para poderem ser vistas, inicialmente, pelo público e fazer parte dos imaginários e planos dos turistas (FALCO, 2011, p. 25). Segundo Bandeira (2013), a mídia tem papel tão importante quanto o avanço nas estruturas de transporte e hospedagem. Mídia, nesse caso, está presente desde os cartões postais até revistas especializadas e sites da internet. Falco (2011, p. 26) recorre a Gastal (2004) para apontar que todos os tipos de deslocamento têm em comum a presença de imagens porque antes de viajarem para um lugar as pessoas já terão entrado em contato com ele visualmente por meio de fotos e narrativas em jornais, internet, cenas de filmes e da TV.

Reconhecendo a importância do audiovisual para a promoção do turismo, o Ministério do Turismo publicou, em 2007, o estudo de sinergia e desenvolvimento entre as indústrias do turismo e audiovisual brasileiras. O documento "tem como diretriz a análise da correlação entre os produtos audiovisuais e a disseminação dos destinos turísticos para a inserção do chamado turismo cinematográfico no contexto nacional” (BRASIL, 2007, p. 3). O estudo tem os set-jetters ${ }^{2}$ como foco e afirma que as locações utilizadas nas produções audiovisuais acabam por influenciar o espectador de forma consciente ou não.

Verifica-se que parte considerável dos estudos que fazem a interlocução entre turismo e telenovelas se apoiam em conceitos ligados ao marketing e a Publicidade e Propaganda - o que demonstra como o olhar para o turismo muitas vezes é direcionado ao consumo. Outros autores fazem uma abordagem da telenovela por meio da concepção de imaginário coletivo. Assim, as imagens que são exibidas pelas narrativas ficcionais são também uma forma de compreender a realidade brasileira: "[...] aposta-se na ideia de que a contemplação dessas imagens pode despertar um conjunto de percepções, favorecendo um conhecimento aproximado do imaginário coletivo brasileiro" (OLIVEIRA; BARRETO, 2004, p. 5-6). Portanto, as imagens que remetem a questões turísticas, como paisagens, atividades ligadas à cultura e ao patrimônio natural, são uma forma de mostrar o Brasil que nem sempre está ao alcance (econômico e físico) do telespectador.

Apesar do cuidado ao fazer afirmações sobre o poder de transformação social das telenovelas, alguns estudos demonstram que há inferências em determinadas regiões. Oliveira e Barreto (2004) se dedicaram à análise da chamada região cacaueira situada ao sul da Bahia,

\footnotetext{
${ }^{2}$ Set-jetters são turistas que tem como motivação de viagem a visitação de sets e locações de filmes e séries.
} 
um local que já esteve na TV através das telenovelas Gabriela (1975/2012) e Renascer (1993), ambas produzidas pela TV Globo. O enredo da primeira, que teve origem num romance de Jorge Amado, contou com o forte protagonismo da jovem Gabriela, interpretada por Sônia Braga, na cidade de Ilhéus. Hoje, “a cidade é repleta de referências a esse universo ficcional, através de nomes de logradouros, casas comerciais, empresas de ônibus, empresas de comunicação (rádio e jornal impresso), entre outros” (OLIVEIRA; BARRETO, 2004, p. 4). Neste caso, identifica-se uma mão dupla de apropriação: de um lado a ficção que se referência na cidade de Ilhéus para contar a história de Gabriela, utilizando-se de seus logradouros, paisagens e costumes e na outra perspectiva, a própria cidade que se utiliza do sucesso da novela para incrementar o turismo. A prefeitura tem reformado prédios que foram referenciados na trama e alguns estabelecimentos foram nomeados com o mesmo nome daqueles que fizeram parte da ficção ou mesmo com homenagens no cardápio, como o Flor da Gabriela - um tipo de chocolate que remete às partes íntimas de Gabriela (OLIVEIRA; BARRETO, 2004, p. 5).

Em 1990, a TV Manchete exibiu Pantanal, de Benedito Ruy Barbosa, telenovela que registrou altos índices de audiência, com picos de até 44 pontos $^{3}$ segundo o Ibope, e impôs uma nova linguagem ao gênero. A gravação de $75 \%$ das cenas in loco contou com alto investimento estético, responsável por conformar uma representação visual do pantanal, contribuindo para a atividade do turismo na região. O estudo de Rocha Filho (2010) mostra que desde que a novela projetou o pantanal, tradicionais fazendas de criação extensiva de gado começaram a receber turistas nacionais e estrangeiros. Um exemplo é o da Fazenda Rio Negro, que serviu de locação para as gravações.

Num contexto mais amplo, podemos pensar ainda nas novelas brasileiras que tem partes da trama gravadas no exterior. Segundo Marcia Tondato (2012), as experiências internacionais nas telenovelas mostram que esse ambiente "de fora" pode trazer mudanças na vida da audiência, que não precisa se deslocar para consumir ou se apropriar dos aspectos que são explorados pela telenovela. Como exemplo, a autora cita as novelas escritas por Gloria Perez, O Clone (2001/2002) e Caminho das Índias (2009), que tiveram trechos gravados em países do oriente, como Marrocos, e que contribuíram para a mudança de comportamento da audiência. "Os espectadores destas novelas (com)viveram em detalhes com o dia-a-dia dos

\footnotetext{
${ }^{3}$ Com referência à cidade de São Paulo-SP. Cada ponto no Ibope equivalia em 1990 a cerca de 40 mil domicílios, totalizando, portanto, pouco mais de um milhão e 700 mil domicílios.
} 
personagens em situações inusitadas para nossa cultura, "aprendendo" novos hábitos alimentares, conhecendo rituais e tabus" (TONDATO, 2012, p. 1069).

\title{
3 O ESTILO TELEVISIVO COMO METODOLOGIA DE ANÁLISE DE TELENOVELAS
}

Para compreender como determinadas estratégias utilizadas pela telenovela podem colocar um destino turístico em evidência e criar um imaginário idealizado sobre determinado local, é acionada a metodologia de análise do estilo televisivo, como preconizada por Jeremy Butler (2010). A metodologia se faz importante pois, de acordo com Butler (2010), o estilo é formado por qualquer padrão de características de som-imagem de todo texto televisivo que cumprem uma função e constroem significados. Conforme afirma Simone Rocha (2016), o estudo do estilo é importante pois torna possível uma melhor compreensão de programas televisivos, permite discutir sobre o contexto cultural no qual ele está inserido e, ainda, analisar as ferramentas utilizadas por seus realizadores:

\begin{abstract}
A iluminação de uma cena orienta nossa compreensão dos valores morais que um personagem carrega. Um corte que justapõe imagens de um carro descendo estrada abaixo e de uma jovem garota perseguindo um determinado produto gera uma metáfora visual. Tomadas em câmera lenta de velocista indicam, paradoxalmente, a potência de sua velocidade aumentada (ROCHA, 2016, p. 24).
\end{abstract}

Metodologicamente, Butler (2010) propôs a divisão da análise do estilo televisivo em quatro dimensões: descritiva, analítica, avaliativa e histórica, das quais apenas duas serão executadas em nossa análise devido aos nossos interesses de pesquisa ${ }^{4}$. Primeiramente, no âmbito descritivo é preciso que, além de enunciar características e técnicas em cenas individuais, sejam avaliadas a utilização destas em contextos ampliados. "O que significa dizer que a mesma atenção que roteiristas, diretores, cinematógrafos, editores e demais profissionais dedicaram à construção de um texto deve ser empregada na desconstrução do mesmo" (ROCHA, 2016, p. 31). Dessa forma, fica claro que no processo descritivo estão envolvidas análises de contexto de produção em determinado tempo e espaço. Portanto, a fase descritiva inicia a interpretação do estilo.

\footnotetext{
${ }^{4}$ Sobre a terceira dimensão, a avaliativa, Rocha (2014) diz que para Butler ainda não há normas estéticas sistematicamente definidas capazes de guiar a avaliação do estilo televisivo, pois esta dimensão pode se compor por termos problemáticos e com carga ideológica, como "visão artística", "elegância", por exemplo. Por sua vez, a dimensão histórica compreende a evolução estilística. Como essas duas dimensões não são compõem os objetivos desta pesquisa, elas não serão contempladas na análise.
} 
A dimensão analítica, ou funcional, se relaciona com os propósitos do estilo. Nesta etapa, o trabalho do pesquisador se concentra em entender e apresentar como essa função é cumprida, buscando padrões de elementos e as relações entre eles. Butler determinou oito funções que o estilo televisivo pode cumprir. São elas: a) Denotar: diz respeito a tudo que é apresentado na cena. As pessoas posicionadas, os objetos aparentes, o plano de fundo, entre outros elementos; b) Expressar: se relaciona com as características que provocam emoções. Elas podem ser subjetivas (a cena mostra tristeza) ou pretenderem emocionar o espectador (a cena faz me sentir triste); c) Simbolizar: é a capacidade de materializar conceitos abstratos; d) Decorar: é o estilo pelo estilo. Também chamado de maneirismo, é a utilização do estilo sem a intenção de transmitir um sentido; e) Persuadir: se relaciona com o esforço feito para convencer o espectador a consumir produtos, bem como atrair e manter a audiência; f) Interpelar: diz respeito às estratégias utilizadas para chamar a atenção do telespectador, que, geralmente, divide a atenção da TV com outras atividades. Esta, se faz presente por meio de sons, iluminação ou outros recursos para convocar o público para acompanhar momentos específicos; g) Diferenciar: é expressa pelos recursos que são usados para distinguir um programa por outro do mesmo gênero, como diferentes telejornais, por exemplo; h) Significar ao vivo: essa função é composta por elementos que indicam que um conteúdo está sendo transmitido ao vivo ou que quer dar esta impressão, utilizando estratégias como a baixa estabilidade de imagem, por exemplo.

As cenas do corpus, que será parcialmente explicitado em seguida, foram primeiramente descritas num esforço de desconstrução do objeto, mas a descrição integral não será incluída neste artigo por conta de limite de espaço. Em seguida, na fase funcional do método de Butler, é realizada a análise, evidenciando as funções desempenhadas pelo estilo e buscando as relações entre telenovela e turismo. Ou seja, analisa-se de que modo as funções do estilo em O Outro Lado do Paraíso cooperam para a construção visual de um Jalapão idealizado.

Para que seja viável a análise de um conteúdo audiovisual tão extenso quanto uma telenovela, é preciso delimitar um trecho, uma série de capítulos que será o corpus do trabalho. Para tal, nos apropriamos do critério do "evento narrativo" para a delimitação desses trechos. De acordo com Rocha (2017), tais eventos são compostos por uma trama que envolvem acontecimentos que garantam um desenvolvimento da história, como casamentos, romances, traições, disputas de poder, entre outros. O evento narrativo pode durar vários 
capítulos ou não. Para este trabalho, foi escolhido o evento narrativo denominado "Encontro entre Clara e Gael”, transmitido no primeiro capítulo da novela.

O evento consiste na formação do triângulo amoroso formado por Clara, Gael e Renato. O médico (Renato) conhece Clara em uma passagem pelo bar de Josafá, avô da moça. Os dois posteriormente começam a trabalhar no quilombo da região do Jalapão. Clara, como professora infantil e Renato realizava atendimentos médicos à comunidade. Gael chega ao quilombo por meio de indicações da população local, pois está em viagem de férias, interessado em conhecer os atrativos do Jalapão. Viajando de moto, o encontro com Clara acontece quando o protagonista chega à plantação de capim dourado do quilombo, onde as mulheres realizavam a colheita. Clara e Gael se encontram novamente numa festa popular da comunidade (Figura 1). A sequência faz referência à Festa da Colheita do Capim Dourado, realizada na Comunidade Mumbuca, a cerca de $22 \mathrm{~km}$ do município de Mateiros, na região do Jalapão.

Figura 1 - A Festa do Capim Dourado em O Outro Lado do Paraíso
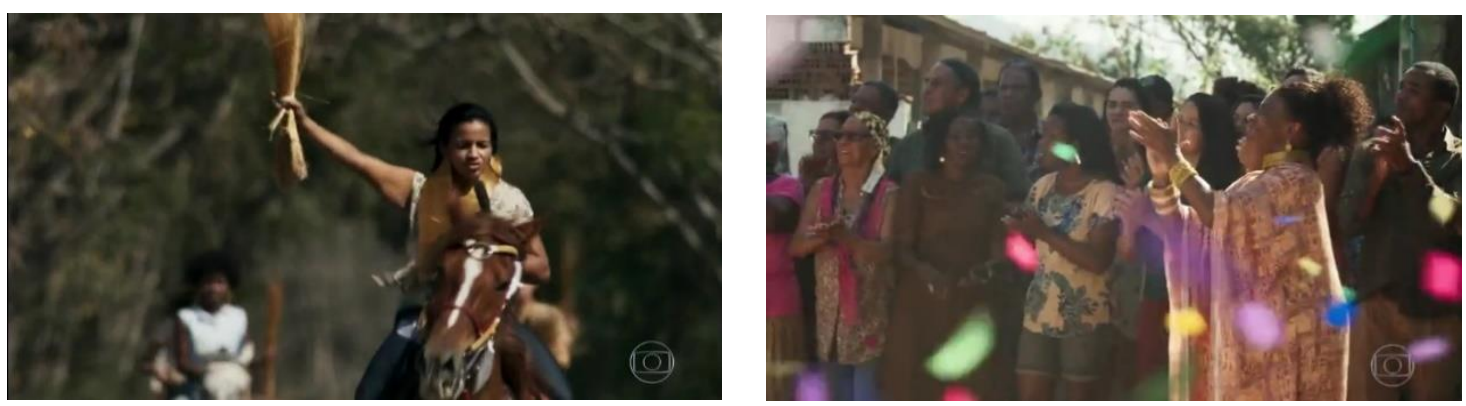

Fonte: TV Globo, 2017.

$\mathrm{Na}$ festa, o casal se conhece efetivamente e conversam brevemente. O rapaz, então, pede a moça que o leve para conhecer a região, diz querer "ser surpreendido". Quando Clara vai se despedir de Renato, ocorre o primeiro atrito entre os protagonistas que disputarão a moça durante a narrativa. A sequência das cenas mostra o casal visitando diversos atrativos naturais do Jalapão.

O evento descrito evidencia o Jalapão, colocando-o em primeiro plano, visto que os demais acontecimentos da telenovela não contribuem, ainda de forma decisiva, para o andamento da trama, dando a ideia de que a ambientação é mais importante e, por isso, deve ser mostrada, quase como um marketing turístico. Após observações do objeto empírico, foi possível identificar que alguns elementos do estilo da telenovela contribuem de forma mais evidente para a representação visual do Jalapão, sendo considerados por nós como os 
operadores analíticos: Enquadramento de câmera; Performance/Atuação dos personagens; Cenário e Edição.

\section{ANÁLISE: RASTROS DE UM ESPAÇO IDEALIZADO}

O evento narrativo analisado se desenvolve durante o primeiro capítulo de O Outro Lado do Paraíso e, dessa forma, o telespectador ainda não tem completo domínio sobre a personalidade dos protagonistas e de que forma a trama vai se desenrolar a seguir. Portanto, em diversos momentos, elementos estilísticos são empregados com a função de dar "pistas" e construir a história que será apresentada. Os enquadramentos em planos gerais com grande amplitude de imagem, os cenários em estradas, e a performance do protagonista em uma moto (Figura 2), tem a função de simbolizar que o personagem vai em busca de aventuras. $\mathrm{O}$ figurino, composto de roupas pretas, capacete e óculos escuros compõem a imagem misteriosa de um "bad boy". A falta de closes impede que vejamos o rosto do protagonista por um longo período, simbolizando o mistério que ele carrega.

Figura 2 - O motociclista e o mistério na tomada de câmera
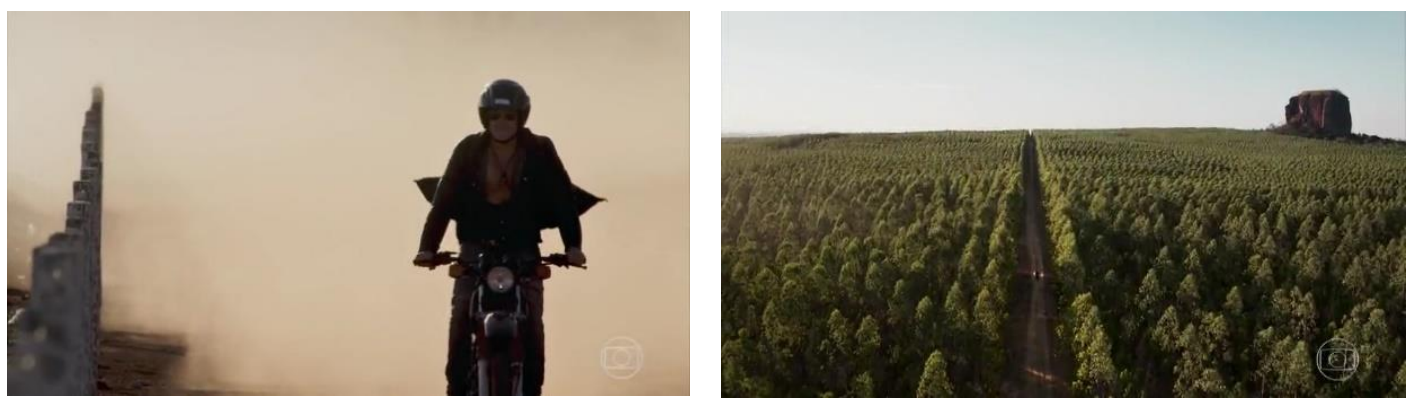

Fonte: TV Globo, 2017.

Em outra sequência, Gael entra em uma disputa de velocidade com cavalos de corrida. Nela, foram utilizados recursos estilísticos como a performance do personagem, que se levanta do assento da moto diversas vezes, e a edição, intercalando imagens lentas e rápidas, com a função de expressar sensações de liberdade e adrenalina. Por outro lado, as sequências de Clara contam com elementos do estilo que a colocam no lugar de boa moça. Nas imagens em que a protagonista visita a colheita do capim dourado a luz do sol transpassa seu corpo. $\mathrm{O}$ estilo, portanto, cumpre a função de simbolizar Clara como uma pessoa iluminada. A performance desenvolvida nessa sequência, em que a personagem brinca com crianças e pega uma delas no colo, é outro elemento usado para compor a mocinha. 
Nos momentos em que esses dois personagens estão juntos, passeando pelo Jalapão, a iluminação cumpre papel importante. As imagens são compostas por um jogo de luz e sombra, muitas são escuras e em contraluz (Figura 3). Esse recurso estilístico simboliza a existência de obscuridade dos protagonistas e da relação - o amor que nasce nas sombras, onde ambos não se conhecem bem. Isso se relaciona também com a própria concepção da narrativa, que aborda "o outro lado" do paraíso tocantinense e com a abertura da novela, que usa do jogo de luz e sombra em paisagens naturais, simbolizando que em tudo há o outro lado, inclusive no paraíso.

Figura 3 - O jogo de luz e sombra
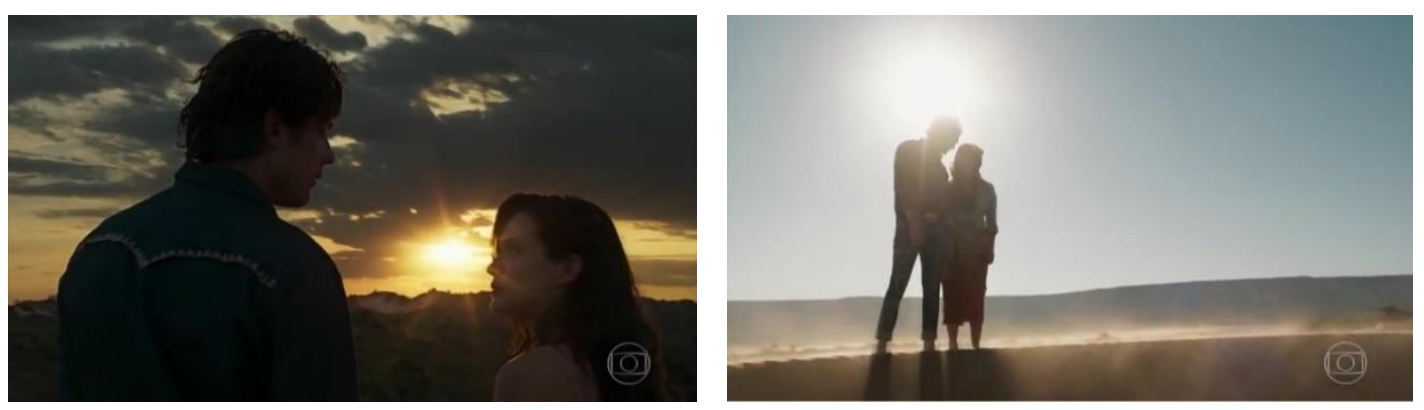

Fonte: TV Globo, 2017.

Nota-se, que os jogos de luzes, as movimentações de câmera com tilts e travelling e a valorização do plano aberto faz-se construir a imagem idealizada do Jalapão como destino turístico. Assim, o estilo desempenha em muitos momentos a função denotativa. Não há a intenção de ser implícito; ao contrário, o objetivo é mostrar de forma clara como a região é bela e deve ser conhecida. Portanto, o cenário, enquadramento, performance e diálogos são elementos estilísticos utilizados para reforçar e comunicar essa mensagem sem interferências. Num gesto interpretativo, o apelo turístico empregado pela novela aborda três frentes: I) a estrutura receptora do turista; II) cultura local como atrativo e III) valorização das belezas naturais.

\subsection{A estrutura receptora do turista no Jalapão}

Para avaliar o potencial e as condições de uma localidade de receber o fluxo turístico é necessário se atentar para a infraestrutura de apoio do lugar. Fazem parte desse âmbito todos os equipamentos públicos ou privados que proporcionam bem-estar para residentes e visitantes, como sistema e condições de transporte, saúde, saneamento básico, água, energia e outros (BRASIL, 2011). As diversas sequências de imagens do trajeto de Gael desbravando o 
Jalapão em sua moto pelas estradas, denotam que o sistema de transporte, mesmo que quase todo composto por estradas de terra, é eficiente. O enquadramento e a edição evidenciam estradas largas e retilíneas, que levam o personagem corretamente a diversos atrativos e não há nenhum tipo de problema na viagem - como buracos, atoleiros -, visto que ela não é realizada em um carro com tração. Até mesmo a poeira oriunda da estrada de terra que poderia incomodar o motociclista não aparece no evento, já que não há outros veículos trafegando nas estradas, o que demonstra a composição de uma situação idealizada.

Em contrapartida, ao pesquisar sobre roteiros de viagem para o Jalapão encontra-se informações conflitantes. Segundo sites especializados (VIAGEM, 2019), as vias de acesso aos atrativos da região não são asfaltadas e, devido ao solo arenoso, a recomendação para quem visita o Jalapão é viajar em um carro com tração 4x4. A sinalização das estradas não é eficiente, a densidade demográfica é baixa e em muitos lugares não há sinal de telefone ou internet, portanto, é um destino difícil para aqueles que viajam sozinhos, como Gael na novela.

Outros fatores a serem observados para se avaliar a potencialidade de um destino é a sua oferta de equipamentos turísticos, tais como serviços de alimentação, meios de hospedagem, diversão, etc., e também o nível de envolvimento e aceitação da comunidade local com o desenvolvimento do turismo (ALMEIDA, 2009). Ambos foram abordados nas cenas que compõem o evento narrativo do encontro de Clara e Gael. Há planos em que o protagonista aparece almoçando em um restaurante - que por meio do cenário e adereços simplórios denota que aquele é um estabelecimento simples.

Ao praticar um turismo com caráter de informalidade, Gael parece viajar por conta própria, sem auxílio de guias ou agências e, assim, vai em busca de orientações solicitando-as diretamente para os moradores locais. No âmbito da performance, os moradores locais são receptivos ao turista (Figura 4 ). 
Figura 4 - A hospitalidade dos moradores locais
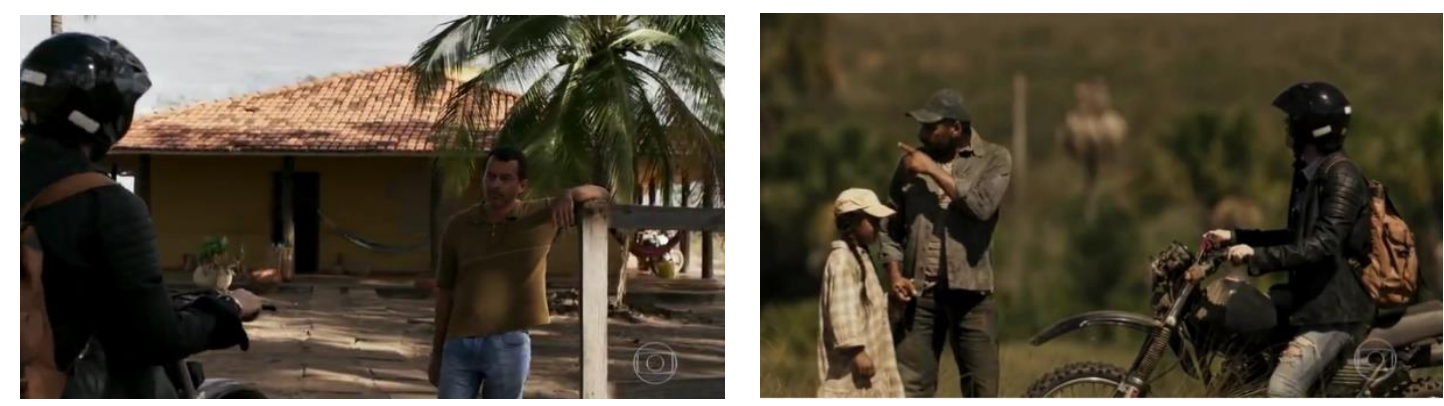

Fonte: TV Globo, 2017.

$\mathrm{Na}$ primeira sequência em que esse contato ocorre, o residente vai ao encontro e aguarda com despojamento a solicitação do forasteiro. Após a pergunta feita por Gael, o personagem responde com prontidão, de maneira tranquila. $\mathrm{O}$ morador recebe e conduz Gael até o atrativo indicado. O protagonista conhece, então, a suposta fábrica de refino de drogas de Pablo Escobar. Esse atrativo não é estimulado oficialmente pelo governo local, pois não aparece na lista de atrativos do roteiro "Encantos do Jalapão" disponível no site da Secretaria de Turismo do Estado do Tocantins, provavelmente em razão das controvérsias que envolvem a figura de um traficante. Dessa forma, o conhecimento popular dessa espécie de "lenda" no Jalapão também ganha destaque na narrativa, valorizando-o. Ao fim da sequência o morador ainda sugere outro passeio, o que exalta a sabedoria dos locais sobre o que pode ser conhecido na região.

A hospitalidade da comunidade do Jalapão é simbolizada também em um segundo contato, agora no quilombo. A performance é o principal elemento utilizado com essa função. Gael cumprimenta o morador, ele devolve o cumprimento e vai ao encontro do protagonista. O turista pergunta sobre a localização do campo de capim dourado e, na resposta, o personagem se esforça para explicar, indicando com palavras e gestos. No diálogo, o morador é educado e se dirige a Gael como "senhor". No fim, ele se despede do turista com um aceno. Além dessas duas situações, a representação visual dos moradores locais como povo acolhedor e amigável é coroada pela aceitação e disponibilidade de Clara em levar Gael para conhecer mais atrativos da região.

\subsection{Cultura local como atrativo}

Em O Outro Lado do Paraíso os atrativos culturais do Jalapão foram representados visualmente por meio da produção do artesanato com capim dourado e da festa popular em comemoração à colheita do material, ambientados no povoado Formiga. O artesanato feito 
com a planta é típico da região do Jalapão. A prática de criar mais de 50 produtos, como bolsas, pulseiras, mandalas, entre outros, passada por gerações, se expandiu e atualmente representa importante fonte de renda para a população do Jalapão (TURISMO, 2019).

Com o recurso da performance, na sequência em que são apresentados os produtos feitos pela comunidade, o estilo cumpre a função de denotar a importância daquela cultura para o quilombo por meio da fala "É do capim dourado que nóis vive aqui" dita pela personagem Raquel (Erika Januza). O potencial de divulgação dos produtos de capim dourado foi explorado em uma reportagem exibida pelo Jornal Anhanguera $1^{a}$ Edição, afiliada da Rede Globo em Tocantins, que destacou o crescimento nas vendas do artesanato após as sequências aqui analisadas $(\mathrm{G} 1,2017)$. "Se o capim dourado já fazia sucesso quando a divulgação era mais no boca-a-boca, imagina agora que está em destaque na novela $O$ Outro Lado do Paraíso" diz a voz em off da repórter. Uma das artesãs entrevistadas afirma que após o primeiro capítulo houve aumento de encomendas.

Nessa e em outras sequências da novela, o enquadramento - que não destaca os personagens -, a performance e os diálogos são utilizados para compor a função denotativa, que explicitamente funciona como uma vitrine de produtos locais - como no caso do artesanato de capim dourado - e não contribui para o desenvolvimento da trama. O capim dourado ganha destaque também ao ser pano de fundo para o encontro - e o instantâneo interesse - entre os protagonistas Clara e Gael, que acontece durante o momento da colheita do material.

Figura 5 - Os detalhes e a alegria na colheita do capim dourado
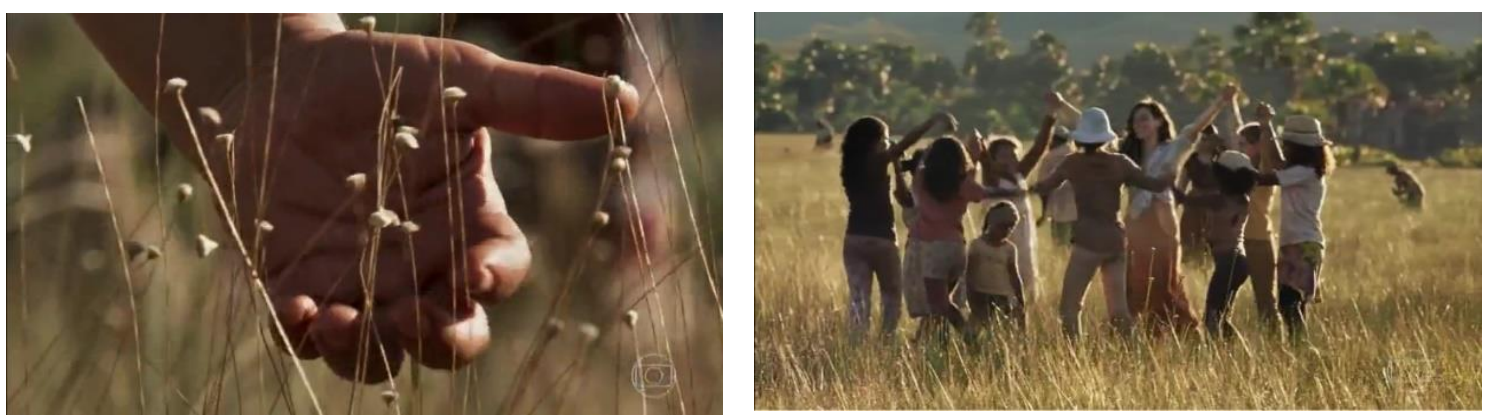

Fonte: TV Globo, 2017.

Nessa sequência, o enquadramento em plano detalhe feito (Figura 5) na mão de uma das mulheres, a performance dos atores - que estão sorridentes -, a música de fundo - que traz certo lirismo para a composição da cena -, e o uso da luz do sol - aparente em muitos planos, 
mas não retratado como algo que deixa a colheita mais desgastante -, são recursos que colaboram para a função decorativa do estilo. O esforço aqui é tornar o processo de colheita esteticamente belo, apagando os conflitos e o desgaste envolvido nessa prática.

O patrimônio cultural do Jalapão foi abordado em mais um momento importante da trama. A Festa da Colheita do Capim Dourado é o ambiente em que se desenrola o início do romance dos protagonistas. O evento marca o início da colheita e possui apresentações, shows, cavalgadas, desfiles, além de palestras e debates. A cena que retrata a Festa da Colheita tem início com uma edição de cortes rápidos que simbolizam a diversidade de manifestações culturais da comunidade. $\mathrm{O}$ desfile a cavalo, mostrado na sequência, é uma das atrações da programação do evento em Mumbuca. Apesar da intenção da novela de abordar a festa popular do quilombo, nesse momento, o estilo cumpre, novamente, uma função decorativa. Os adereços de cena coloridos, como o estandarte, as fitas e os enfeites fazem com que a festa seja similar às demais festas populares brasileiras. A novela acaba por criar uma generalização das manifestações culturais da região, fazendo com que o folclore pareça sempre igual, não importando a individualidade de cada local. $\mathrm{Na}$ novela, os ornamentos feitos com fitas, papel crepom e outros poderiam corresponder às festas populares do congado ou reinado em Minas Gerais, por exemplo.

Os únicos elementos que denotam a singularidade do Jalapão são: 1) a música em off dos violeiros que aborda a cultura local e diz de onde provém tal tradição dita na letra: do Jalapão; e 2) a viola de Buriti, instrumento típico da região, que é destacada em três planos diferentes.

\subsection{Valorização das belezas naturais}

Ao longo de todo o evento narrativo, pôde-se verificar inúmeros planos que possuem alguma paisagem natural como cenário. Quando se trata de mostrar as belezas naturais do Jalapão, o estilo cumpre a função denotativa e de forma bastante explícita muitas vezes dá protagonismo para os atrativos em vez dos personagens na trama. São variadas as imagens que envolvem belos cenários da região e que, em contrapartida, pouco colaboram para o desenvolvimento da narrativa. $\mathrm{O}$ uso excessivo de planos gerais, por exemplo, evidencia o cenário e faz com que os personagens não sejam os mais importantes aspectos da imagem. Muitas vezes, eles aparecem pequenos e em contraluz, não sendo possível observar suas expressões faciais de felicidade ou paixão. Portanto, nesses momentos a função expressiva foi deixada em segundo plano. Os usos da voz e dos diálogos em off, com imagens do Jalapão 
sobrepostas às falas e aos corpos, também contribuem para a função claramente denotativa, com as imagens sobrepostas aos elogios a aquele ambiente.

\section{CONSIDERAÇÕES}

Por meio da metodologia de análise estilística foi possível identificar que em O Outro Lado do Paraíso os operadores foram utilizados para cumprir duas principais funções: denotativa e decorativa. São eles: a) enquadramentos em planos gerais - utilização de drones que se movimentam para ampliar a profundidade de campo, a escolha por enquadrar produtos e cenários em detrimento aos personagens; b) encenação - diversidade de cenários, performance dos atores que caminham, fecham os olhos ou abrem os braços, iluminação com a luz do sol aparente; c) som - diálogos que exaltam a beleza e a cultura de um lugar e músicas de fundo que falam sobre relaxar e descansar; e d) edição - cortes rápidos com variados planos de paisagens, imagens que se sobrepõem a diálogos.

A novela recorre a essas funções com o objetivo de exaltar o que há de bom e de belo de maneira explícita. Quando se trata das sequências que possuem características do Jalapão, como as que retratam o passeio do casal e a cultura do capim dourado, são raros os momentos em que há lugar para o implícito e as funções expressiva e simbólica são pouco recorrentes. Portanto, o que se deseja, aqui, é mostrar como o lugar é visualmente atraente, possui uma rica cultura popular e uma ampla variedade de atrativos. O povo é acolhedor e trata bem o turista. As estradas são boas. Há bons restaurantes. A colheita é um momento bonito, que deve ser apreciado como fez Gael ao receber a indicação de um morador. A Festa do Capim Dourado é uma oportunidade para conhecer a cultura popular expressa na dança e na música. A natureza é imensa e pode ser aproveitada com caminhadas e mergulhos.

A frequente presença de casais aponta ainda para um apelo em divulgar o Jalapão como um destino romântico - sendo um local que pode ser relacionado com a própria noção de paraíso, onde as pessoas vivem o amor e há ausência de conflitos. Neste ponto, questionase, em uma autocrítica, o emprego e os sentidos do termo "destino idealizado" para se referir aos objetivos deste trabalho ao longo do processo de desenvolvimento. O Jalapão em $O$ Outro Lado do Paraíso é idealizado para quem? Para determinadas minorias (PAIVA, 2005), a novela pode ser vista como promotora de um turismo discriminador, que fecha as portas para a diversidade e para os conflitos que fazem parte da sociedade.

A partir de tudo o que foi dito, é possível afirmar ainda que a telenovela se utiliza de recursos do estilo para dar visibilidade à atrativos naturais e culturais de um lugar. $\mathrm{O}$ 
predomínio de imagens do Jalapão em detrimento a dos personagens é um exemplo disso. Ainda assim, os elementos da narrativa não são deixados de lado, já que o desenvolvimento da trama também ocupa um lugar importante e pode, ainda, contribuir para que o espectador queira viver o que vivem os personagens e visitar as locações de uma gravação - apesar das ressalvas descritas no caso das minorias.

Pelo âmbito do consumo, a narrativa ficcional seriada pode ocupar um espaço privilegiado em “vender” um destino turístico, pois insere o melhor dele nos capítulos, criando uma relativa idealização do local e, por consequência alimenta o desejo de conhecêlo. Funciona como uma publicidade ou uma revista de turismo em que os principais atrativos são mostrados em sua melhor forma, com o benefício de que, na telenovela, eles são envolvidos em uma narrativa que, como já vimos, alcança uma parcela considerável da população no Brasil.

Esse potencial turístico pode ser um caminho de governantes e outros empresários do setor para fazer um destino despontar no competitivo ambiente turístico. Por outro lado, $O$ Outro Lado do Paraíso ao intencionalmente dar enfoque à cultura e a natureza do Jalapão também serve como "janela” para lugares ainda pouco conhecidos de um país de proporções continentais como o Brasil. Comunidades e paisagens podem ser vistas por pessoas que, por diversos fatores sociais, econômicos e culturais, não poderiam conhecê-las. Portanto, há também uma função social importante e que deve ser pensada também de forma mais inclusiva para que se amenize a exclusão daqueles que ainda permanecem no "outro lado do paraíso".

\section{REFERÊNCIAS}

ALMEIDA, Marcelo Vilela de. Matriz de Avaliação do Potencial Turístico de Localidades Receptoras. Revista Turismo em Análise, São Paulo, v. 20, n. 3, 2009, p. 541-561.

BANDEIRA, Milena Berthier. Cidades turísticas e seus imaginários: o olhar da imprensa especializada. Revista Rosa dos Ventos, v. 5, n. 3, 2013, p. 439-450.

BRASIL. Lei 11.771, de 17 de set. de 2008. Dispõe sobre a Política Nacional de Turismo, define as atribuições do Governo Federal no planejamento, desenvolvimento e estímulo ao setor turístico.

Diário Oficial da União, Brasília, 18 set. 2008.

BRASIL. Ministério do Turismo. Inventário da oferta turística. Brasília, DF, 2011.

BRASIL. Ministério do Turismo. Estudo de sinergia e desenvolvimento entre as indústrias do Turismo \& Audiovisual brasileiras. Brasília, DF, fev. 2007. Disponível em: 
<http://www.turismo.gov.br/sites/default/turismo/o_ministerio/publicacoes/downloads_publicacoes/Es tudo_Completo_Cinema.pdf> Acesso em: 08 ago. 2019.

BUTLER, Jeremy. Televison Style. New York, London: Routledge, 2010.

FALCO, Débora de Paula. Narrativas Turísticas: imaginário e mídia na experiência urbana do turismo. Revista Rosa dos Ventos, v. 3, n. 1, 2011, p. 24-38.

G1. Estreia de O Outro Lado do Paraíso aumenta venda de acessórios de capim dourado. TV Anhanguera, 30 set. 2019. Disponível em: <https://g1.globo.com/to/tocantins/noticia/estreia-de-ooutro-lado-do-paraiso-aumenta-venda-de-acessorios-de-capim-dourado.ghtml>. Acesso em: 21 ago. 2019.

GASTAL, Susana. Turismo, Imagens e Imaginários. São Paulo: Aleph, 2004.

HAMBURGER, Esther. Telenovelas e interpretação do Brasil. Lua Nova, n. 82, 2011, p. 61-86.

HJARVARD, Stig. Midiatização: teorizando a mídia como agente de mudança social e cultural. Matrizes, São Paulo, v. 5, n. 2, 2012, p. 53-91.

LOPES, Maria Immacolata. Telenovela brasileira: uma narrativa sobre a nação. Comunicação \& Educação, São Paulo, n. 26, 2003.

OLIVEIRA, Rodrigo; BARRETO, Maria. Telenovela e identidade regional: considerações sobre o papel da ficção televisiva no incremento turístico no sul da Bahia. In: XXVII Congresso Brasileiro de Ciências da Comunicação - Intercom, 2004. Anais... Porto Alegre: Intercom, 2004.

PAIVA, Raquel; BARBALHO, Alexandre (Orgs.). Comunicação e cultura das minorias. São Paulo: Paulus, 2005.

ROCHA, Simone. O estilo televisivo e sua pertinência para a TV como prática cultural. Revista FAMECOS, Porto Alegre, v. 21, n. 3, 2014, p. 1082-1099.

ROCHA, Simone. O estilo televisivo - E sua pertinência para a TV como prática cultural. Florianópolis: Insular, 2016.

ROCHA, Simone. Estudios visuales y estilo televisivo: porque no existen medios puramente visuales. Chasqui. Revista Latinoamericana de Comunicación, Quito, n. 135, 2017, p. 297-316.

ROCHA FILHO, José Fonseca. No ritmo das águas, na cadência das boiadas. A inserção do turismo nas fazendas de criação extensiva de gado bovino no Pantanal de Aquidauana/MS. 2010. 248 f. Dissertação (Mestrado em Geografia Humana) - Programa de Pós-Graduação em Geografia Humana, Universidade de São Paulo, São Paulo, 2010.

TONDATO, Marcia Perecin. Viajando com a telenovela: o turismo ficcional como amplificação de universos simbólicos e materiais. Revista Comunicación, v. 1, 2012, p. 1031-1046.

TURISMO. Secretaria de Turismo do Estado do Tocantins. Disponível em: $<$ https://turismo.to.gov.br/regioes-turisticas/encantos-do-jalapao/principaisatrativos/mateiros/artesanato-em-capim-dourado/>. Acesso em: 01 set. 2019.

VIAGEM. Jalapão: como chegar, hotéis, restaurantes, passeios e mais. Revista Viagem e Turismo, 2019. Disponível em <https://viagemeturismo.abril.com.br/cidades/parque-estadual-do-jalapao/>. Acesso em 07 ago. 2019. 
WTTC. World Travel \& Tourism Council. Disponível em: <https://www.wttc.org/>. Acesso em: 23 set. 2019.

Original recebido em: 06 de outubro de 2019

Aceito para publicação em: 30 de junho de 2020

José Tarcísio da Silva Oliveira Filho

Professor do Programa de Pós-Graduação em Comunicação e do Curso de Comunicação Social-Jornalismo da Universidade Federal de Roraima. Doutor (UFMG) e mestre (UFJF) em Comunicação Social. Jornalista (UFV). É líder do laboratório Laboratório Lugares e Espaços Contemporâneos: jornalismos, migrações e audiovisual (CNPq/UFRR).

Rafael Barbosa Fialho Martins

Professor dos cursos de Jornalismo e Publicidade e Propaganda da Universidade Vale do Rio Doce (Univale). Doutor e mestre em Comunicação Social pela Universidade Federal de Minas Gerais. Jornalista pela Universidade Federal de Viçosa

Natiele Lopes Costa

Jornalista pela Universidade Federal de Minas Gerais. Atuou em projetos de extensão e em telejornalismo.

\section{(C) $\odot \otimes(0)$}

Esta obra está licenciada com uma Licença

Creative Commons Atribuição-NãoComercial-CompartilhaIgual 4.0 Internacional 